\title{
OBITUARIO
}

\section{ALDO ORLANDO BORDÓN}

(1933-2006)

El 8 de noviembre de 2006, el Ing. Agr. Aldo Orlando Bordón, muere trágicamente en la ciudad de Villa Angela, en el Chaco, como consecuencia de un asalto.

El Ing. Agr. Bordón, chaqueño de nacimiento, nació en General Pinedo el 10 de agosto de 1933. Sus estudios secundarios los realizó en Presidencia Roque Sáenz Peña.

Llevó a cabo sus estudios universitarios en la Facultad de Agronomía de la Universidad Nacional de Tucumán. Se recibió el 6 de diciembre de 1961 y casi inmediatamente se dedicó a la investigación en pasturas. Fue alumno de J. H. Morello y tuvo como compañeros a Carlos Saravia Toledo y Roberto A. Neumann.

Más tarde obtuvo el título de M. Sc. en Producción de Pasturas. Desarrolló su actividad profesional en El Colorado (Formosa), Pre-

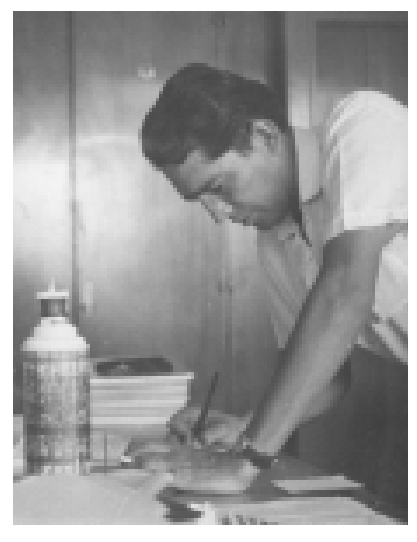
sidencia Roque Sáez Peña (Chaco), Pirané (Formosa), siempre en dependencias del INTA. Después de jubilarse en 1994, pasó a vivir a Villa Angela.

A raíz de sus estudios de pasturas naturales documentó sus observaciones con ejemplares de herbario. Son importantes sus colecciones del Impenetrable, en el oeste chaqueño.

Publicó poco pero escribió mucho. Sus publicaciones son:

Bordón, A. O. 1968. Aspectos de la actividad desarrollada por el INTA en el oeste de la provincia de Formosa y propuesta para el aprovechamiento de los ambientes. Idia 252: 45-63.

- 1971. Reactivación hídrica de Chaco y Formosa. Boletín 62, Estación Experimental Roque Sáenz Peña, INTA. 41 pp.

- 1981. Pasto salinas (Munana - Pennisetum ciliare Link) como heno de pié. Boletín 76, Estación Experimental Roque Sáenz Peña, INTA. 11 pp.

- 1983. Comentarios e idiogramas sobre vegetación de la provincia del Chaco emergentes de una muestra de descripciones de vegetación en relación a series de suelo. Boletín 86, Estación Experimental Roque Sáenz Peña, INTA. 100 pgs.

— , E. J. López, R. Duarte \& R. L. Pellegrino. 1977. Estudio de los recursos forrajeros naturales del noroeste del Chaco. I. Localización e identificación de informantes calificados en el primer módulo de trabajo. Estación Experimental Roque Sáenz Peña. Departamento de Producción Animal. Pasturas. Documento 1053. 38 pp.

Dejó numerosos manuscritos que tratan principalmente sobre manejo de praderas naturales. Tanto sus manuscritos como su herbario de más de 3000 ejemplares están ahora depositados en el IBONE. Estas colecciones realizadas principalmente en lugares áridos complementan las de don Augusto Schulz, también guardadas en nuestro instituto. 